\title{
WHY NOT A SUPERMARKET NAVY?
}

\section{The South African Navy has inherited many customs and traditions from its predecessors and one of these is that 'a warship must look like a warship'.}

\section{Introduction}

Up to and just after World War II warship's were obvious extensions of a colonial powers authority. They were designed as visible symbols of power and as the ultimate in fighting machines. Gleaming brightwork, sparkling paint, holystoned decks and freshly scrubbed awnings combined with conspicuous gun turrets enabled these ships to fulfil their roles of showing the flag and impressing the natives. The sight of one of these ships putting to sea with her rails lined with uniformed sailors and her band playing on the quarterdeck left no doubt whatsoever in the minds of those watching that here was a highly potent instrument of war.

Many officers still serving in our navy first went to sea at this time and thus through their initial impressions and later rigorous upbringing came to consider the outward appearance of these ships as the desirable norm for a warship. That they are not alone in this thinking is borne out by the large number of conventional looking warships still being built by many navies of the world.

\section{Changes in Warship design}

The changes in weaponry over the last few decades however have led to substantial changes in warship design so that today the big gun capital ship has given way to the often small and utilitarian missile carrier. The through-deck cruiser is replacing the aircraft carrier, the nuclear submarine has become the capital ship of the future and ever increasing numbers of fast patrol boats are joining the navies of the world. Many modern examples of naval architecture are anything but impressive. There are sharply discernible trends towards small and rakish looking ships with their silhouettes completely spoiled by ugly and outsize missile bins on one hand to large ships with towering and ungainly superstructures dwarfing tiny and lonely looking missile launchers on the other. The ships of the Western nation navies appear to look less and less warlike with each new generation and it is possibly only the Russian navy which still today appears to place a strong emphasis on the fact that their ships must look impressive. This is probably because they of all navies are most being called upon to carry out that same role once carried out by the navies of the former colonial powers.

\section{The situation in South Africa}

In the South African Navy we too have stubbornly hung on to the conservative concept of a warship. Our frigates have proudly carried on the post World War II tradition of being properly Navy-like and seen to be so. ('Pusser-navy' is the term normally used.) This idea is carried through to the majority of our small ships as well as they also date from the same period. Even our new and later ships although small are unmistakably warships of the conservative type and an understandable source of pride to those who sail in them.

The time is repidly approaching however when our frigates followed by our minesweepers and various other ships will have to be phased out as they come to the end of the period of life for which they were designed. In fact a heavy replacement programme will shortly have to be launched just to keep our Navy able to perform the basic functions of such a force. The financial implications of such a replacement programme however are quite frankly staggering.

Warships, especially custom built warships of the type favoured by the South African Navy, cost a lot of money. Acquisition programmes for new warship classes can today start off in the vicinity of RM 300 and escalate from there due to inflation and rising building costs. Design and development costs are colossal and building periods are measured in years. Politics also enters into warship construction. During the lengthy acquisition period allegiances alter which force the customer to be particularly careful as to where he places his order. This also in many cases tends to add to the costs involved. After our recent experiences with France it would obviously be preferable for us to build our future warships right here at home in the RSA, even though the building of custom-built warships in this country 
would literally cost us a fortune. Our need for an adequate seaward defence system is however so vital that we must of necessity accept the costs involved whilst at the same time searching for a means to cut them.

This question has obviously already been the subject of much thought and serious planning by many senior and highly qualified naval officers. Various answers have been raised which in turn invariably give rise to considerable controversy not only in the Navy but also sometimes in the Defence Force as a whole. Projects are already under way in the Navy's replacement programme and this article is by no means a criticism of those projects which after years of work are now on the brink of fruition. To a keen naval and maritime observer however it appears that for future projects, and indeed in the present ones, we are overlooking a remarkably easy way of saving costs through being hide-bound in conservatism and what other navy's might think of us.

Are we not caught in a mental straight-jacket because of the tradition that 'a warship must look like a warship'? If you ask a naval officer to describe a warship to you he will automatically, in our navy, form a mental picture of a conservative type warship unless he happens to be a submariner or serving in a strike-craft. But is a warship of necessity a frigate, or strike-craft or even a minesweeper? The crew of the boom defence ship SAS SOMERSET no doubt view their ship as a warship but she would only come to light as an afterthought if the man you questioned had as his idea of a warship a destroyer carrying out a high speed antisubmarine attack or the type of ship we spoke about at the beginning of this article. The definition of a warship according to the Concise Oxford Dictionary is simply "a ship for use in war", which is not very helpful but covers the case of SAS SOMERSET. In the true sense as most of us would see it a warship could be simply described as an armed (or un-armed) vessel representing her governments authority. In the conflict which gave birth to our navy the early South African Naval Forces did not consist of the gleaming giants described in the opening paragraphs but of small converted whale-catchers and trawlers which were just as much warships in the true meaning of the word - certainly in the eyes of their crews and country they were warships!

After we have drawn up our Staff Requirement and then sat down and planned, designed and built to come up with a variation of a traditional warship at great cost, are we not in fact re-inventing the wheel? Are the needs and requirements of our navy and circumstances so unique that with all the types of ships shown for instance in 'Janes Fighting Ships' we have to design yet another one? The answer to that question could very well be 'yes' because obviously we do not always have ready access to all the plans, designs and equipment needed to acquire a ship such as those shown in the publication just mentioned. The answer might also be 'yes' because the role of the ship as envisaged by the planners might very well be unique, because the role of the ship determines her design and not vice-versa.

\section{The design of South African ships and more specifically the availability of designs}

To discuss the design of our ships we should therefore first have a look at the roles they will be called upon to play. I am going to break away from this logical sequence for a few moments however to first draw the readers attention to the availability of designs. I intend doing this by means of the following anology.

Suppose you were not particularly wealthy, lived in a small town and wanted to purchase a new lawnmower. You had only one large shop in town which had a large range of these appliances - let us for convenience sake and at the risk of advertising call it the OK Bazaars. You would call on them and after inspecting what was on offer would buy the one most suited to your needs. If the ordinary standard lawnmowers on offer were unsuitable to your needs because you needed bigger wheels or a tilted carriage or something similar the odds would be that with the aid of the salesman and a local garage or engineering works you would be able to make the necessary adjustments to the standard machine so that it suited you. It is highly unlikely that you would sit down with the salesman and design a lawnmower from scratch.

If however you lived in a big city and had a choice of stores so that if your requirements were not met by one shop you could then shop around at all the others, as well, you would be more than likely to find exactly what you were looking for. If you were a particularly wealthy man you could probably call in at a number of engineering shops and even have a custom-made lawnmower built for you to your own unique requirements.

From the above we can draw an anology to the 
South African Navy. Some years ago a senior officer in the Navy who has since retired is supposed to have said something to the effect that 'We don't want a supermarket navy?' At that time we could be likened to the man in the big city. We had lots of money and a choice of suppliers who were prepared to sell or build for us. At the present moment we compare with the man in the small town. We are isolated and cut off from the major warshipbuilding centres and hence thrown back on our own shipbuilding industry, the supermarket of our anology. Why then insist that the salesman should assist in designing a new product when one is available from off the shelf?

Here of course one could be venturing into deep water because obviously the ships available on our shipbuilding shelf are with the exception of the strike-craft currently under production not by any means the type of ship which those who feel that a warship must look like a warship would be interested in acquiring. But then neither were the whale-catchers and trawlers I mentioned once before as being used by our navy in time of need. I am not for a moment suggesting that the circumstances are remotely the same but simply once again pointing out that a 'warship' comes under a variety of guises.

Before World War II a firm known as C. G. Smiths had a brand new sugar carrying coaster built which ended her life forty years later as a guano-boat. For a brief spell in her life however she was a salvage ship in the SA Navy and nobody can deny that HMSAS. GAMTOOS is remembered today not as a coaster or guanoboat but as a warship. She was of course whilst under the guise of a warship, fulfilling the role of a salvage ship. This illustrates the point that different types of warship fill different roles which in turn influence their designs. The GAMTOOS however was not designed as a salvage ship but adapted into a role normally fulfilled by a specially designed and built ship. By all surviving reports she performed her function admirably. Is there a replacement for our present salvage ship in the pipeline one wonders, and if so will she be specially built or will we try and adapt something as we did with the GAMTOOS and thus save ourselves a considerable sum of money? I would venture a guess that after a cursory look around we will decide that there is nothing suitable available and set out to design and build our own replacement!

But should we not with this example in mind take a good look at what we have and the role we want our ships to play and see in how many cases we can match the two together?

\section{The adapting of ships for other purpose by other nations}

Other nations have done this most successfully and an unbiased paging through say 'Janes Fighting Ships' will show that this practise is fairly common amongst the navies of the world. Denmark for instance does not hesitate to base her warships on what are obviously variations of merchant hulls whilst the ultraconservative Royal Navy has an Antarctic patrol Ship, HMS ENDUR. $A N C E$, which started off life as a Danish freighter.

On a recent visit to Chile, a country which was at the very brink of war with Argentina at the time, I had the honour of being allowed to serve in an attack transport. This ship, the AQUILLES, was an integral part of a war-time task force but had started out in life as a Faroe Islands passenger ferry. One of our consorts, the YELCHO, was used for Antarctic patrol and relief work and had originally been a fleet tug. A solitary warship doing a lonely and gale swept patrol amongst the channels south of Tierra del Fuego was an armed trawler. A submarine tender in Valparaiso was launched as a Baltic car ferry. For all their disparité and commercial origins these ships were armed and commissioned warships of a nation in a state of readiness for war and were highly efficient in their assigned roles.

\section{Arguments in favour of the conversion of South African ships to suit specific roles}

Before we shrug the above circumstances off as purely 'South American' let us consider our own peculiar circumstances. Without attempting to summarise either the SADF's 'Forecast of Operations' or the various papers which have been written on the subject, the role of the South African Navy's ships boils down to maintaining a credible deterrent to discourage sea-borne terrorism; preventing sea-borne incursions of our coast line or belligerent isolations of our territorial waters and exclusive economic zone; the support of combined and special operations and the waging of offensive and defensive mine warfare. Purists may argue that there are in fact many more tasks which have not been listed but by-and-large those are the broad tasks of our naval ships. With these in mind let us have a look 
and see what we have on the shelf which can fit those roles.

Dorman Long and Van der Bijl (Dorbijl) is situated in Durban and builds commercial ships for both the home and export markets. In 1976 they were building oil rig supply ships and exporting them to the North Sea oil industry. From the accompanying photograph one can readily see that this type of ship with its long clear afterdeck is highly suitable for adaptation. They originated as a type in the Gulf of Mexico for servicing oil rigs and have proliferated about the offshore oil fields of the world since then. They are highly maneouverable and extremely versatile. The low after deck and heavy winch situated aft have resulted in this class of ship replacing the older type of buoy layer cum net layer with horns forrard and a ship like this could well replace SOMERSET or eventually SAS FLEUR. Their tanks for the stowage of cement plus deck space render them useful for inshore logistic support and their high standard of sea-keeping and long range has proved them ideal for lengthy periods of offshore patrolling and station-keeping. The Americans have many of these in the Gulf of Mexico and have experimented with various configurations of these as patrol vessels, diving support vessels and salvage and logistics craft. ${ }^{1}$ Have we had a closer look at what we were previously exporting to see if our Navy can use them in one of those roles?'

Dorbijl also built a series of coastal container ships for Messrs Unicorn Lines and a picture of the BERG is shown here to illustrate the following points. These ships have a good turn of speed and a long endurance. Controversy has raged for years in various technical journals about how easy it is to convert a container ship to a warship configuration, especially a helicopter carrier. Each separate container lends itself either singly or as part of a batch to adaptation as a self contained module.

It is thus possible to construct portable radio shacks, radar and operation rooms, sickbays, galleys, workshops etc. The tops of the containers themselves give a level and open surface which could readily be made usable as a flight deck. The various modules commensurate with the ships role could be stored ashore until needed and then rapidly placed aboard and literally plugged in to the ships previously adapted power supply. A large sea-worthy patrol ship of this nature capable of steaming rapidly to a point and then doing a slow speed deployment could

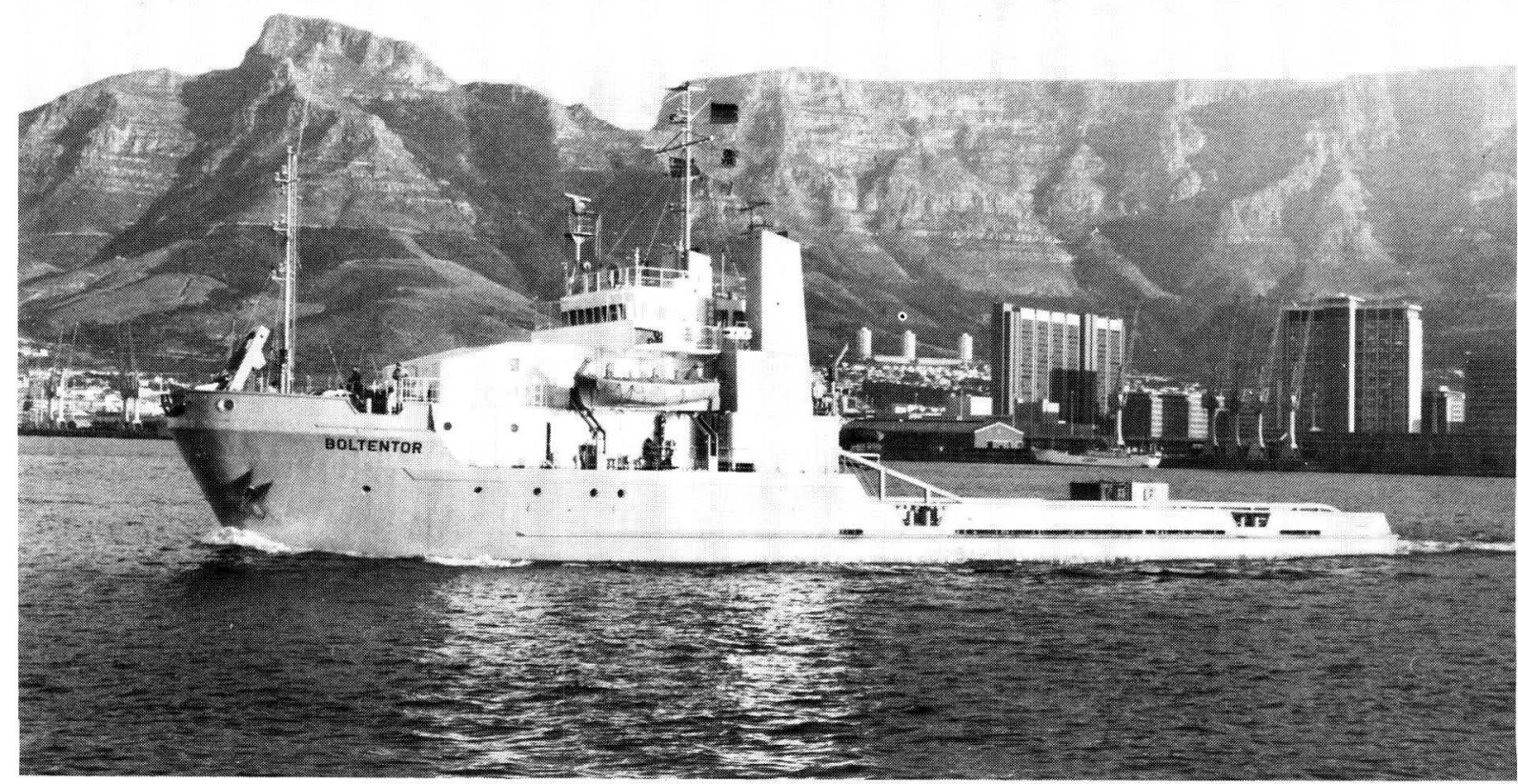

German oil rig supply ship 'Boltentor', of a type previously constructed in Durban. A low afterdeck, high maneouverability and good turn of speed makes this type of ship readily convertable into a large number of naval roles. 


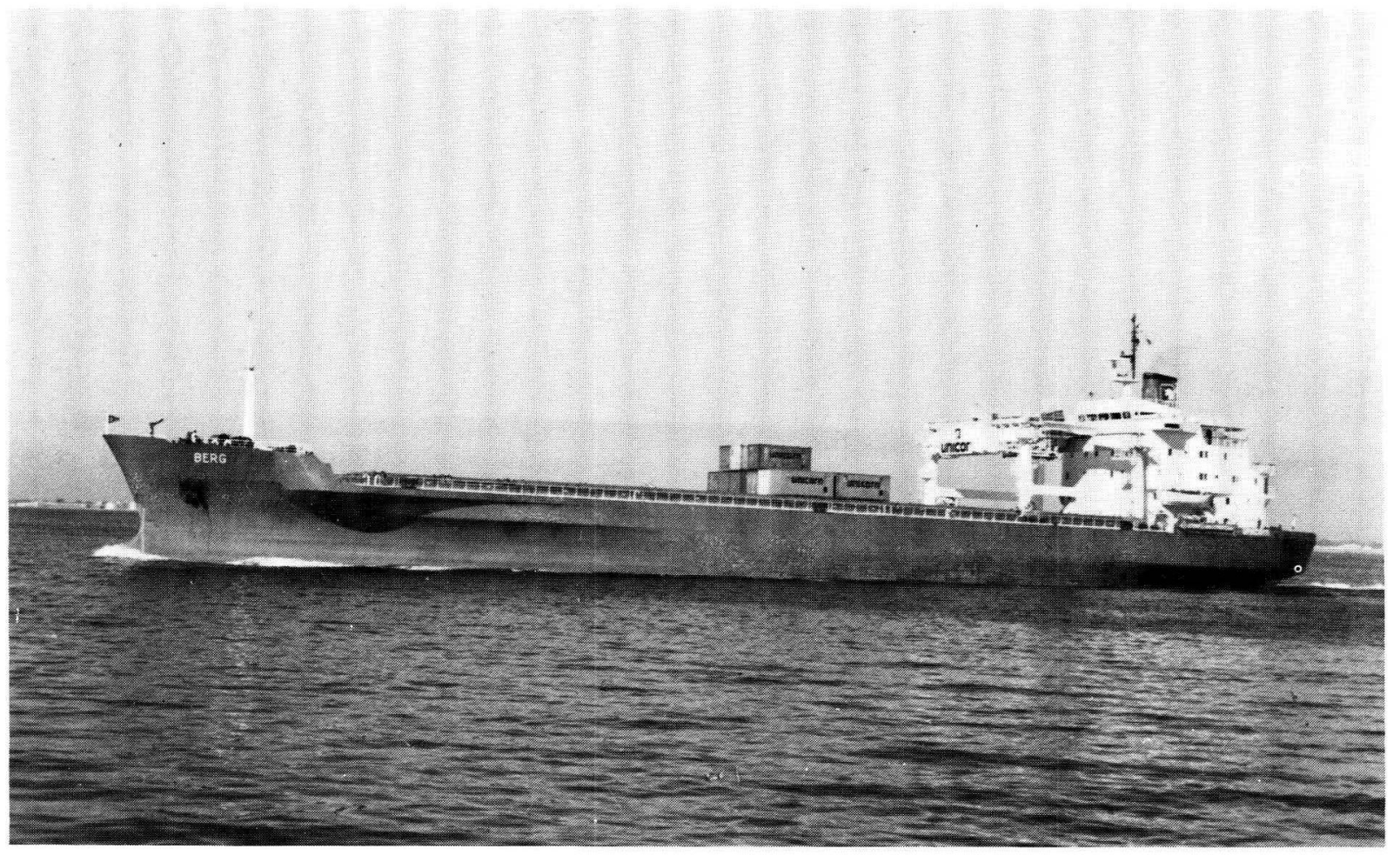

The South African coastal container ship 'Berg' built in Durban. Removal of the movable gantry crane and level stack of container modules gives rise to a large number of useful naval roles, not the least being a flexible helicopter capacity.

The South African Trawler 'Anemone'. Although foreign built she is one of a large number of readily available Hulles of a type being investigated for mine sweeping duties overseas.

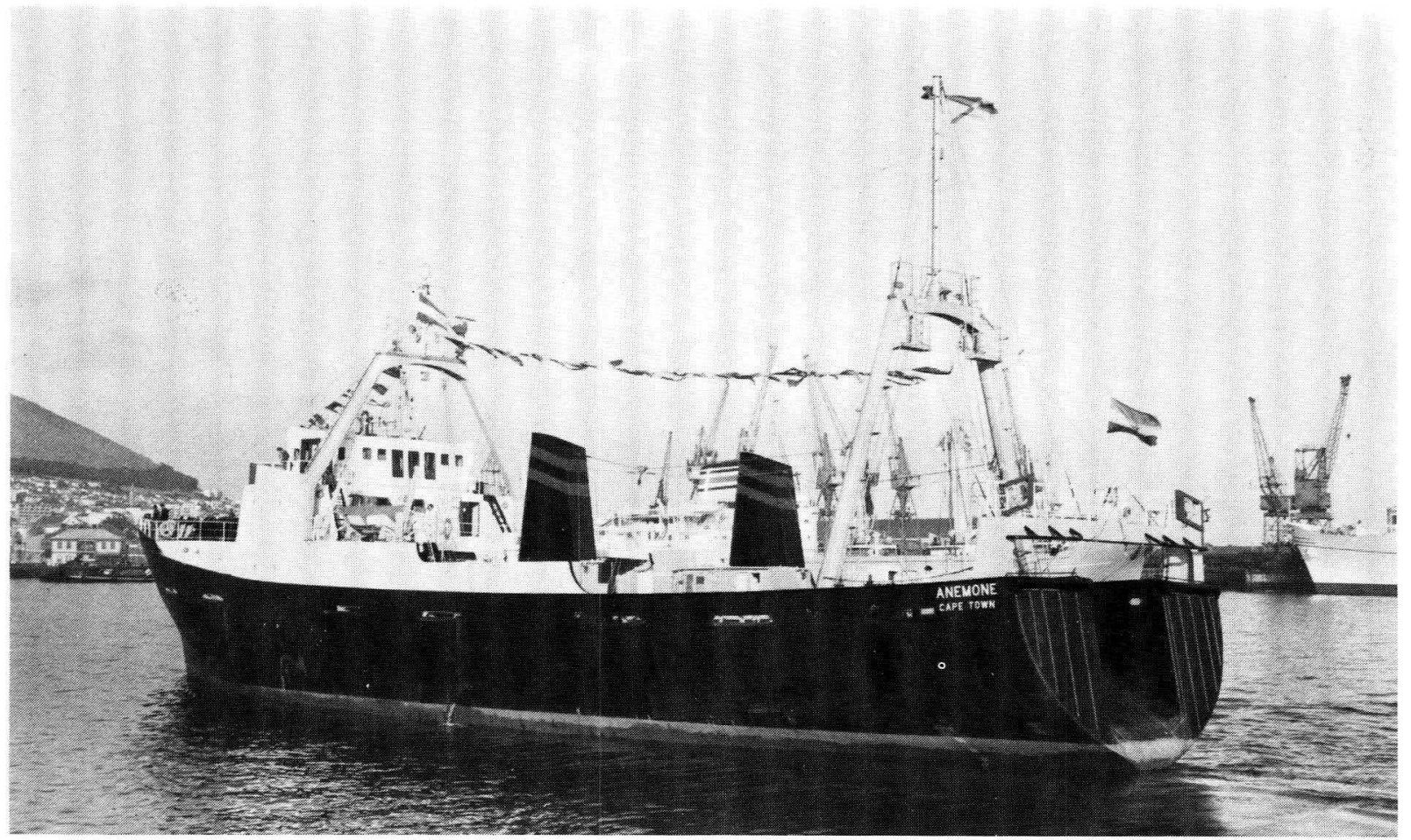


well be used in conjunction with a helicopter or in an electronic warfare role. It would not be particularly lean and rakish but it might well be successful in such a role.

During the Icelandic Cod War the British initially deployed frigates such as ours against the Icelandic gun-boats and trawlers. In the heavy weather and no holds barred ramming and net cutting operations they rapidly discovered that their frigates were not nearly as efficient in the fishery protection role as an ordinary commercial deep sea tug and wasted no time in chartering ships of this type into the Royal Navy. Although we do not at present have a matching role in our Navy our own shipbuilding industry has proved with the SA JOHN ROSS that it can build deep-sea tugs quite effectively and it seems fairly obvious that in time of war this ship and her magnificent sister, the SA WOLRAAD WOLTE$M A D E$, would require little conversion into first class warships.

The South African Navy possesses a number of CONISTON class minesweepers which in some cases have been converted into patrol vessels. As minesweepers these vessels are now starting to show their age and will shortly need to be phased out. The normally conservative British have encountered this same problem and although they are building a new class of minesweepers have found that commercial stern trawlers can with very little effort be converted into minesweepers for use by their reserve basis. $^{2}$

It appears highly logical. The ships have heavy winches and tow their gear astern. Large clear working decks aft and a sloping ramp to the water make for ease of handling and rapid launching and recovery of gear and inflateable boats. Tunnel screws, high maneouverability and excellent seakeeping ability combine to make a most useful type of ship. Their main disadvantage is the fact that they have a steel hull rather than wood or glass fibre which poses an obvious query about their usefulness in any situation involving magnetic mines. However we are going to have to replace our sweepers eventually and although one hopes we will be able by that time to afford custom built ships for the minesweeping role these trawlers might also be looked at in the light of other recent British experience. They have found that the most suitable type of ship for North Sea patrol work is a derivation of a commercial trawler design which they call the ISLES class. Granted that we do not have North Sea conditions here but for years we have been complaining about our own sea-conditions and how difficult it is to find suitable warship hull shapes to cope with them. In the meantime our trawlers have been putting to sea in those very same waters on a daily basis. Why don't we copy Whitehall's example and charter one of those large and well-found trawlers such as shown in the photo from Capetown or Saldanha. A simple evaluation period might result in some useful thoughts on adapting the design into a useful all-round type of light warship.

\section{Conclusion}

The main point which must be conveyed across to the reader is that nobody is suggesting that we take or commandeer existing ships other than in a state of dire emergency. Rather let us take existing local commercial designs and building experience and adapt them towards fast and cheap local production. Not only will it save us a lot of money but as pointed out above it is not really very far out of line with what is becoming a readily acceptable practice.

Let us break away from our cherished and traditional notions of what a warship should look like. At the situation Leadership Seminars so many of us have attended in the Defence Force they teach us to think 'outside the nine dots'. Let us do so when thinking of our future navy. What is so awful about a fast converted merchantman in an offshore patrol role except that it does'nt look like the popular conception of a warship. Would the running costs be the same as those for a frigate? It's highly doubtful - you certainly would'nt need anywhere near the same number of crew members for a start. Ships of commercial origin can also be readily repaired by competitive facilities with a subsequent easing of reliance on the dockyard and a corresponding cut in costs.

With the cost of warship construction screaming upwards so that it becomes more and more difficult to get our naval budget for replacements approved we should pocket our pride, even if temporarily, and have a good hard look at what we can buy off the shelf on our own home ground. We have a famous South African saying that ' $n$ Boer maak altyd 'n plan' and with a basic fast hull we would probably be surprised at what we can accomplish by way of producing various warships for various roles. A precedent in this respect was set for us as long ago as the 1930's when British planners of the time transformed a whale-catcher 
hull design into the highly successful FLOWER class corvette. If it has been done once it can be done again!

A coat of grey paint, a uniformed crew, a naval ensign and some readily visible armament can transform any reputable commercial vessel into a businesslike and efficient warship provided that she is carefully matched to her role. As we have said before there is no likelihood of our Navy taking on an enemy KASHIN class destroyer or depth-charging submarines. Our Navy's war is going to be the protection of our coastline and maritime interests by patrols, mine warfare and support operations. There is no need for our ships to look impressive or indeed anytning other than efficient as they go about these rather uninspiring tasks. Is there therefore any really valid reason you can think of apart from that 'a warship should look like a warship' as to why we should not have a supermarket navy?

* Car I. C. Little, SAN is SSO FP (N) at Defence Headquarters, Pretoria.

* * With the above article Cdr Little won the Military Essay competition of 1979.

References

1. Information supplied by American Bureau of Shipping.

2. Quarterdeck Magazine Sep 78. 